Iranian Conservation Science Journal - ISSN 2588-2740

\title{
The Role of Intangible Cultural Heritage in Cultural Globalization
}

\author{
Mahin Sohrabi Nasirabadi
}

Faculty of Arts, Alzahra University, Tehran, Iran

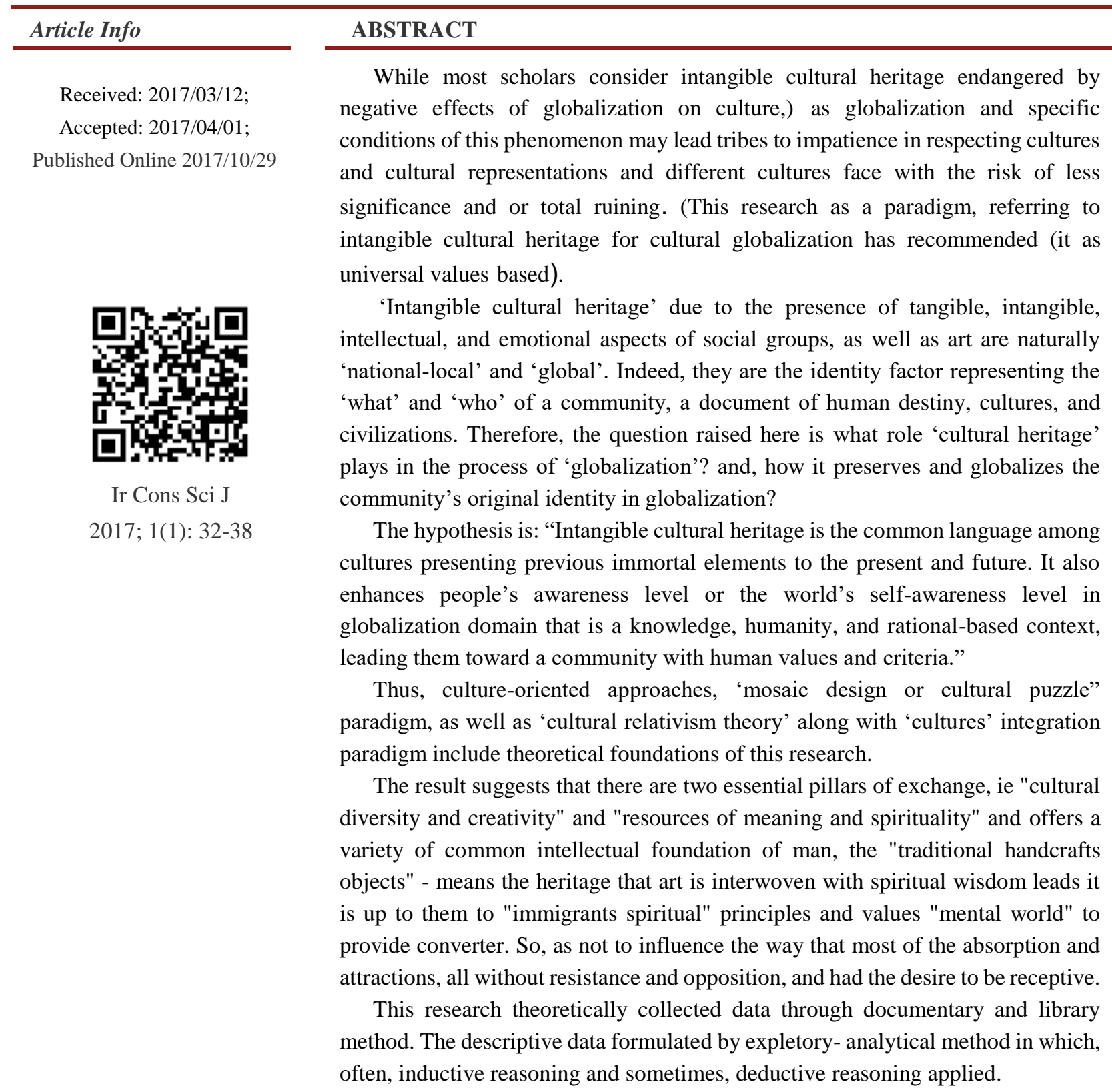

Keywords: Intangible Cultural Heritage, Cultural Globalization, Cultural Diversity Spirituality, Traditional Handcraft.

Corresponding Information: Mahin Sohrabi Nasirabadi, Faculty of Arts, Alzahra University,Tehran, IRAN., Email: ma.sohrabi@alzahra.ac.ir

Copyright () 2017, Ir Cons Sci J. This is an open-access article distributed under the terms of the Creative Commons Attribution-noncommercial 4.0 International License which permits copy and redistribute the material just in noncommercial usages, provided the original work is properly cited.

\section{Introduction}

Science, music, painting, novel, poem, traditional art, and all cultural phenomena embracing 'tangible and intangible cultural heritage' are humanitarian and global as not only represent human imagination, dreams, 
aspirations, and suffering but also, seek for general audience. These are freedom immigrants requiring no certificate crossing borders, they move from the internal, private levels of human life to its most external dwelling wherever a common language and understanding emerge. They invited by the hosts rather than aggressively entering; thus, not only any destruction occurs, but also they revitalize and renovate what have been. This is what referred spiritual immigration.

Therefore, globalization can be possible by cultural continuity, which brings peace, friendship, humanity, justice, human right, etc. through tangible and intangible cultural heritage. This potential comes from the issue that cultural heritage guarantees our identities; is meaning oriented full of symbols; and the most important, carriers extra material concepts; thus, it will be the most competent factor in creating culture and unity realizing a real dialogue such that considered as the most developed way of interacting to the inside and outside world and especially fellows.

Main part of cultural heritage is 'traditional artifacts', the meaning of which carried by their material body; indeed, these are first-hand sources and documents utilized for studying and transferring meaning and spirituality, as reliable, real, and live references. In fact, these crafts are largely functional; they exist both in native and non-native cultures carrying traditional life messages. Thus, in addition to maintaining and revealing identities, they perform as spiritual immigrants. The immigrants come from tribes, hearts, and reflections crossing the borders through attraction and appealing rather than dominance.

The present writing reviews the aforementioned issues clarifying the significance of the ignored case of cultural globalization. Such new approach identifies and introduces position and status of the cultural heritage and traditional artifacts in the introduced globalization paradigm, in particular globalization theory.

'And his signs are the creation of heavens and earth and the diversity of your tongues and colors' (Holy Quran, Al-Room, Verse 22)

\section{Experimental Procedure}

Culture-oriented approaches, 'mosaic design or cultural puzzle" paradigm, as well as "cultural relativism theory' along with 'cultures' integration paradigm include theoretical foundations of this research.

This research theoretically collected data through documentary and library method. The descriptive data formulated by expletory-analytical method in which, often, inductive reasoning and sometimes, deductive reasoning applied.

\section{Results}

The result suggests that there are two essential pillars of exchange, i.e. "cultural diversity and creativity" and "resources of meaning and spirituality" and offers a variety of common intellectual foundation of man, the "traditional handcraft objects" - means the heritage that art is interwoven with spiritual wisdom leads it is up to them to "immigrants spiritual" principles and values "mental world" to provide converter. So as not to influence the way that most of the absorption and attractions, all without resistance and opposition, and had the desire to be receptive.

\section{Discussion}

\subsection{Cultures integration paradigm in globalization}

In the case that 'culture' considered as the heart of globalization phenomenon and the attendance of 'global cultures' as outcome of cultural diversity, dialogue, interaction, and exchange, globalization interwoven by 'identity' concept; thus, identity plays a critical role dealt with different approaches in cultural globalization. Satisfaction and happiness may not achieve without individual and social identity; the objective and end of any activities is satisfying human soul and body.

Therefore, it can be stated that all human activities, even economy and policy, are cultural, as the culture possess the power of penetrating over borders and creating multidimensional identities, and can establish a broad scope of communication systems and interaction. However, some believe that globalization has Yanus nature meaning that leading to improved human culture and life and progressed civilization, on one hand; destroying any humanity due to greedy aggression and abusing, on the other hand.

Thinking about globalization in cultural dimension also clearly reveals its dialectic feature.

Globalization is not a 'one way' process merely making events follow great global structures; rather, requires local intervention in global processes. This concept is clearly implied in the wellknown slogan of the 'green movement' namely 'think globally, act locally' demonstrating that globalization follows a cultural policy originating from an obvious collective and cultural narration of what a 'good life' requires. This means that 'culture'- national, local, native, and regional cultural identities- closely related, not physically, free from space 
and location constraint due to existing of fast and wide communication equipment. Or in other word, experience distances (location/ physical) in another way, consciously and unconsciously talk each other, deliberately and unintentionally the interaction flow emerges; this is what called a cultural world in which any culture participate in terms of what pays and receives, making the 'global culture' together.

This culture is diverse as much as shareholders' diversity; it has adaptable, unified components reviewing themselves, as well as permutation and metamorphosis; this is inherent in culture, which is dynamic rather than being static. This indicates recognizing 'cultural diversity' originating from human peripheral and environmental interpretation, its history, others' status, and future. This perspective provides the cultural view and issues including penetration and cultural linkage, combined (integrated) globalization, and linking up to independence; however, in interaction with transnational and local conditions. To state the matter differently, realizing cultural difference means accepting (confirming) cultural diversity leading to 'cultural relativity' and consequently, the necessity of 'cultural dialogue and continuity'.

Therefore, globalization is an opportunity benefited by the ability and desire of any individual and community. They can only participate as consumers and or producers, too. This refers to interaction i.e. consuming what others offer and meanwhile provide some productions for others' consumption. This requires plurality and diversity, as producing and consuming the same product may cause a listless, unmotivated trend. Then, it requires searching for diversity sources probably attract consumers to be extracted and consumed. Considering aforementioned, spiritual cultural heritage and traditions are one of the abundant resources, as moved generation-togeneration, meaning frequently extracted and used, and now in the contemporary, they still kept this capability.

\subsection{The relation of cultural heritage and globalization}

'Nationalism' as well as maintain and distributing several identities regarded as one of the significant basics of cultural heritage. Since 'cultural heritage' introduces different identities in this relation, it critically contributes in cultural globalization.

'Cultural heritage' forms our eternal and everlasting mentality belonging to all human kinds monitoring all individual and collective rights, which on one hand, provides particular cultural identities, and global identity or human identity, on the other hand. 'Cultural heritage' creates the humankind collective memory. Any 'cultural craft' is a typical sign of thought, taste, skill, expertise, and human technology showing human trace of foot in history carrying a human message, too. Therefore, 'cultural heritage' distinguished by three characteristics of 'objectivity, historic, and human message'. The status guarantees its 'material and spiritual' dimensions sometimes also named 'tangible and intangible'. This three-dimension structure follows Gestalt system, like its mother namely culture, in which triple values of 'emotional, cultural, and functional' intrinsically or transversally activate and the result of this integration is the tangible form along with spiritual, intangible content.

Benefiting from art, having artistic characteristics, as well as human message in cultural heritage made them 'meaningful forms' carrying 'semantic network'. It means systematic meanings result from thought and emotion, specific intellectual and practical potentials and objectives of a nation; thus, they can play as a resource or the media for dialogue like what they really do in small and big museums around the world. This demonstrates that there exists a shared, common language among cultures realizing the dialogue and cultures' integration through maintaining the diversity of cultural identities. In other word, this common language makes inter- civilizational dialogue possible.

Internal and external cultural communication depends on the communication level of cultural heritage. World's cultural heritage is a living proof of the value and validity of all cultures not making any cultures dominant over the other though, it recalls culture status referring their various values. Moreover, the most moral 'conversation or dialogue' i.e. respecting dialogue parties, offering shared, universal meanings, the ability of processing new shared meanings and exiting confidence and obstruction achieved by cultural heritage dialogue; thus, the first moral teaching of large museums is friendship, reconciliation, and peace. Respect others, responsibility to others, observing original values and enjoying, as well as love for humanity are museum other moral instructions. Another important issue observed in museums is the free access to true information, consider as human rights with moral aspect. Indeed, museum is the globalization maquette. It does not defend the values specific to a culture or value judgments rather is the place of universal values, presence of global thought, global spirit, and global reconciliation. Thus, assuming the unite totality namely the 'world' resembles human cultural heritage museum presenting 'human unity'; this is the outcome of rethinking civilization evidences allowing inventing and creating new social and cultural structures by which human essence discovered. Therefore, 'being global' means understanding global 
heritage. Heritage thinking is globally thinking, participating in the global spirit, which indicates exiting 'cultural marginalization' and taking part in 'global culture' signifies being global.

On the other hand, 'innovative aesthetic', resulted by reading and decoding human heritage is such that removes any obscenity and hatred of human spirit. Presence of cultural heritage in globalizing 'cultural diversity' is along with 'cultural unity' rather than 'cultural division and plurality'; thus, it can be stated that 'globalization' and 'cultural heritage' are interdependent since globalization requires diverse and unity-making software based on culture; further, surviving cultural heritage needs reading and decoding. Interestingly, what considered as tangible and intangible cultural heritage can be found in traditional handicrafts. In other word, all seen in museums are the traditional handcrafts with tangible and intangible values referred as cultural heritage.

\subsection{The relation of globalization and traditional handicrafts}

The term 'traditional art' is the combination of the two words of 'tradition and art'. In fact, 'art', here, is a tool for tradition, any tradition manifests its realities through which, bringing meaning to its traditional context. This function of art is the first closed form of a tradition emerges even before describing and extending that tradition's philosophical and theological systems. This applying function of art for tradition demonstrated and verified where art outperforms philosophy. The tradition is highly valued such that not any forms deserve it as 'sacredness'. So, what is art that achieved this competence and merit even before describing tradition's philosophical and theological systems, revealing the realities? Bell believes that the common, shared quality of all artifacts referring 'significant form'. Lenger3, also, defines art as 'art is creating symbolic forms of human emotion'. Benedetto Croce also expresses that 'art expresses intuition. Further, Kant defining 'beauty' referred to 'no end termination' (extracted from Madad pour, 2005).

'Art' and 'tradition' not only used in association in terms of significance, but also used interchangeably. Thus, if tradition considered as 'knowledge' and 'sacred knowledge' hidden in human essence veiled under curtains; 'art' is the possibility of removing that veil and identifies cognitive elements through the artist's prevailed intuition picturing the observed 'reality' in all built symbolic forms.

This type of art (real art), being competent for tradition attendance, offers 'To Kalon' debunking the intrinsic puzzle of 'Eros'; it is not just a professional or luxury art rather a typical combination influencing people's emotions and ration experimentally even experimentally and intuitionally adds their knowledge. Such type of art helps progressing human movement, as it owns coherence and consistent interpretable basics in its essence evolving around a stable axis; it means that sharing a common spirit between the artist and various commentators.

This great characteristic is efficient in the dialogue between human and cultures; thus, cultural globalization along with agreement and interaction realized by reflection on 'traditional handicrafts'; further, the hidden wisdom leads to joining all people as many human beings more accept material forms comparing thoughts and reflections, and material forms, even in hyper mental level, deeply influence human soul.

These artifacts manifest 'internal issue' at collective level establishing the 'balance' that is indeed the social order (discipline), justice, freedom, and peace; in particular, attract rational disabled individuals through emotional stimulation and create an indirect, voluntarily mediation at community level. However, the first condition is rejecting all hypotheses and believing tradition nature.

In fact, 'traditions' dialogue' would be possible through artistic channels and its underlying symbols. The tradition founded a meaning world through which not only meanings transferred in generation synchronization, but also are prevalent in different times and periods.

Therefore, handicrafts are like sources with the possibility of reproduction and revitalizing the forgotten or declined cases, which cause preserving cultural diversity. Diversity and creativity along with significance unity in crafts' different symbolic forms more monitor 'being global' rather than' globalization', since the spirituality and the emphasized beauty introspective power associate God in its nature face; and in terms of intuitional dimension, put human in the context of goodness and perfection.

Attraction of traditional handicrafts is under the shadow of a hidden truth; in mystic perspective, the function of terrestrial beauty is returning human being to the source of this terrestrial beauty, i.e. its eternal domain, which means attaining the 'unity'. Therefore, these beautiful forms recall what the human being is; the important tools of knowledge acquiring for human particularly attracted in.

Shcwan expresses the most elementary and general basics of traditional art and its characteristics as follow: -"The implemented work is functional that must be relevant with its determined functions. In the case of any 
additional encoding, it must be consistent with object's inherent encoding. There must be no contrast between major and minor rather it requires a typical hierarchic coherence resulting from the encoding purity.

- The behavior with the used raw materials must be aligned with the nature of the raw materials like consistence of the raw materials with object's function.

- And finally, the object is allowed to represent what it really is not an illusionary, since such an illusion associates unpleasant image of uselessness; however, it is frequent in 'classist art."' (Rahmati, 2004; 51-52)

Thus, 'encoding' is one of the two inherent characteristics of traditional handicrafts; but how deal with this coding feature? Is it the only possibility of intellectual elites with the ability of reading and decoding? Public own medium intellect, do these handicrafts offer anything to such population?

The question can be answered using Schwan interpretations "considering encoding total universality will spontaneously solves this problem, as this universality enables sacred art to transfer accessible psychological occurrences in addition to spiritual expressions, disregarding post natural facts and realities derived from Holy history. In contemporary word, it can be stated that such kind of art is deep and at the same time simple and pure; combining of this depth and simplicity is exactly the major characteristic of this scared art (which is part of traditional art). Simplicity or explicitness of this art never caused by spontaneous or artificial contempt rather it manifests normal expressions of human soul (Nafs), whether it is the normal state of middle human or superior.... Thus, if its sacred art [and traditional art] is attracting to intuitive wisdom, it will be appealing for normal human feeling, too. This means that only such art owns a public language" (Rahmati, 2004; 56-57).

Therefore, the traditional art language sacred language is the excellent form is understandable for different times and locations as it is relevant with human normal feeling; thus, it is ongoing along history and geography linking different nations and generations in synchronization. The traditional art diverse language itself causes appealing in addition to comprehensibility and shared vocabularies intrinsic concepts leading to realized relation. 'Simplicity' is the clear feature of this language, as Jesus Christ says, 'behave as 'little children' and 'as simple as doves', since leads to pleasant conversation, brings reliability and confidence, as well as deeper linkages. However, it is not surprising that core criteria of receiving and recognizing meaning and intrinsic extracted from the community's culture and ideology; so that people and communities interpret different meanings from the same form. This is why art and traditional handicrafts, which are some part of tangible and intangible cultural heritage, are proper fundamentals of providing the meaning based on monotheistic ideology.

Disregarding being idealistic, establishing a real dialogue in world arena and the globalization belief is possible through foundations of creating these handicrafts including 'religion', 'mysticism', 'Sufism' and 'generosity'; in other word, three institutes, in general, are necessary to realize this goal 'meaning foundations', 'meaning expression tools', and 'the place or pole of meaning comprehension'.

Therefore, though, traditional handicrafts are negligible comparing great issues such as policy and economy in organizing and directing globalization process, it is not the reality. This is due to the traditional and symbolic privilege carrying 'excellent patterns' or 'archetypes', some get their example reality turning into an 'archetypal' delivering a trend of various and common meanings, exchange readable meanings and symbols before culture encountering in cultural globalization, which is based on interaction and dialogue; meanwhile, provides the unity in addition to guaranteed identities and pluralities. These moving (flying) objects easily cross the borders are the spiritual immigrants welcomed by outsiders' cultures due to common origin and defamiliarization- as formalists believe; this is not a cultural invasion; rather they penetrate through acceptance and attraction.

The similarity and difference of the world traditional handicrafts emerged by 'traditions'. It means that the similarity comes from one and only one tradition, i.e. the unity sacred; and the diversity results from traditions' or the very various sacred forms' differences. Thus, it can be referenced by any culture, as such, the West studies the East, for years, to discover tradition and rediscover the sacred issue.

Traditional handicrafts, in fact, are external forms acquired by benefiting 'tradition' concept explaining the reality. Traditional arts have symbolic language dealing with inspirational signs. The inspiration internally manifested by this art, caused traditional handicrafts saturated with 'natural spirituality'; thus, issues of 'attention' - mind constantly focuses on God- and 'applying fundamentals of practical ethics' bring 'devil fighting' and 'growing merciful intellect' globally establishing these spiritual foundations.

'Mysticism', namely, is the acquired spiritual knowledge through intuition embracing a large part of traditional handicrafts' foundations. It historically has been as human seeking for religion, and exchanged and 
traded among cultures in a typical 'cultural exchange'. Applying mysticism, according to human nature, is more tangible than being rational. Thus, this may emerge in globalization, too. Activating this entrance as well as cultural exchange, on the contrary to religious paradigms, is more possible through traditional handicrafts, due to the presence of art and tradition, encountering less opposite reactions.

However, modernity dimed the value of 'conduct' and ruined the originality of following Sheikh by promoting human egoism, it can never change human nature and the human will always be the 'attracted seeker', whether he likes or not. It means that he is subjected to God appealing and unintentionally an intuitionally discovers such as the practitioners. Many traditional professions run by following 'generosity' custom.

'Generosity' is the other form of spirituality and a characteristic of Islamic spiritual civilization and culture. It originates from Sufism penetrated in professions providing a form of generosity consistent with its nature. Sufism as a conductive approach follows mysticism involved with directly knowing God and attaining spiritual perfection. It tries to consider sacred issues, relying on pretense, focusing on human salvation by the aid of these external forms. Therefore, attending of such spiritual foundations in traditional handicrafts, as a current tradition or custom among professionals, can assign spiritual appearance to industry and business influencing many economic and market perspectives and cause cultural dialogue relying on common, shared language and meaning.

'Professional ethics' is only one advantage of this art, which is effective in redirecting globalization toward human benefits. 'Globalization ethics' requires governing of a 'professional ethics' accessed through traditional handicrafts' basics. This is the paramount as the 'ethic criterion', which is frequently questioned, is not individual or collective taste or judgment, here; rather, it is 'divine satisfaction' and observing 'people's rights' not merely their satisfaction. Profession is a trust granted to traditional artist; God is the owner of this trust and the individual is the trustee. Thus, any behavior or experience may not be allowed; the only permissible behavior is what satisfies God. Therefore, any negligence of professional and occupational responsibilities is breaking the bailment. In this regard, being 'professional' in business is an ethical issue that making the current large professional world free from fears and anxieties. Therefore, remained traditional civilizations in small workshops, still useful, should break the isolation and reestablish innovative professionalism by reading and rethinking.

\section{Conclusions}

Cultural globalization, relying on spirituality, associates with seeing the 'world' as a systematic unity whole. Regarding human being nature, he looks for the truth origin and extreme; and in this structure, the 'common language', 'common understanding', and 'common attitude' works as a background for cultural conversations seeking common ideals, too. Spirituality is the commonality among cultures resulting from human spiritual requirements, which enhances community, under the light of spiritual orientations, in terms of ethics and moral dignity.

Cultural globalization depending on spirituality and mysticism experienced through 'traditional handicrafts' channel embracing different forms of mysticisms such as Sufism (in specific people), generosity (in public and practitioners), and tradition (traditional concept).

Cultural globalization relying on mysticism and spirituality has a unique characteristic due to its artistic and spiritual cultural heritage features. These flying immigrants easily cross geographical borders as well as human boundaries dwelt in the land of thoughts and hearts. This is not an invasion; rather, welcomes and attracts the audience.

Therefore, 'Iranian traditional handicrafts' carrying value system, traditions and beliefs, knowledge, and skills supplied by resources such as religion, mysticism, Sufism, and generosity are spiritual cultural heritage as they are based on wisdom- combination of act and image; if mined, universal, idealistic, and ethical principles will be recovered. Any nations influence globalization as much as its cultural potential and attendance.

Formulating and implementing a proper cultural policy can help in reserving spiritual cultural heritage and create an effective, strong dialogue. These policies must include the capacity and motivateion of cultural creating in individual and social process.

\section{Conflict of Interest}

Authors declared no conflict of interest.

\section{References}

Ahmadi, B. (1996). Truth \& beauty: Lectures on the philosophy of art. Tehran: Nashr-e Markaz.

Madadpour, (2005), Meet Votes, Thinkers about Art. Sore Mehr Islamic Culture And Art Research Institute. 


\section{The Role of Intangible Cultural Heritage in Cultural Globalization}

Bhikhue, P. (2004). The Power of Culture. Globalization and Challenges of the 21 st. century. IRIB Directorate General for IRIB Research.

Rahmati, E. (2004). Art \& Spirituality -A collection of essays on the philosophy of art. Art Academy.

Tomlinson, J. (1992). Globalization and Culture. Cambrige: polity press.
Robertson, R. (1996). Globality: Globalization and Transdisciplinary, in Theory Culture \& Society. London, Thousand Oaks and New Delhi.

Robertson, R. (1992). Globalization: Social theory and global culture (Vol. 16). Sage.

How to Cite This Article:

Sohrabi Nasirabadi M. The Role of Intangible Cultural Heritage in Cultural Globalization. Ir Cons Sci J. 2017; 1 (1) :32-38

URL: http://journal.richt.ir/ics/article-1-25-en.html 